\title{
Paraplegia in a Patient With IgG4-Related Sclerosing Disease: A Case Report
}

\author{
Sung Heon Kim, $\mathrm{MD}^{1}$, Yeon Kang, $\mathrm{MD}^{1}$, Sung Han $\mathrm{Oh}, \mathrm{MD}, \mathrm{PhD}^{2}$, \\ Soya Paik, MD, $\mathrm{PhD}^{3}$, Joo Sup Kim, MD, $\mathrm{PhD}^{1}$
}

Departments of ${ }^{1}$ Rehabilitation Medicine, ${ }^{2}$ Neurosurgery, and ${ }^{3}$ Pathology, Bundang Jesaeng Hospital, Seongnam, Korea

\begin{abstract}
Immunoglobulin G4 (IgG4)-related sclerosing disease is a systemic disease, characterized by mass forming inflammatory lesions which respond well to steroid therapy. Pancreas is the most common site of involvement, and other organ involvements are also common. However, there are only a few reports about central nervous system involvement. We report a case of IgG4-related sclerosing disease which involves spinal cord causing paraplegia. A middle-aged female presented with sudden lower limb weakness. Magnetic resonance imaging showed a soft tissue mass which was diffusely compressing spinal cord along the C7 to T5 levels. Intravenous steroid pulse therapy and emergent operation was performed. The immunopathologic findings revealed IgG4related sclerosing pachymeningitis postoperatively. There was no evidence of other organ involvement. Her neurologic deficit remained unchanged after two months of comprehensive rehabilitation therapy.
\end{abstract}

Keywords Immunoglobulin G, Spinal cord compression, Paraplegia

\section{INTRODUCTION}

Immunoglobulin G4 (IgG4)-related sclerosing disease is a recently defined disease entity. It has a diffuse or mass forming inflammatory reaction rich in IgG4-positive plasma cells associated with fibrosclerosis and obliterative phlebitis. Pancreas is the most common site of involvement. Hepatobiliary tract, salivary gland, orbit, and lymph node involvement are also common [1]. Multiple organ involvement can occur simultaneously and may

Received February 7, 2014; Accepted May 28, 2014

Corresponding author: Yeon Kang

Department of Rehabilitation Medicine, Bundang Jesaeng Hospital, 20 Seohyeon-ro 180beon-gil, Bundang-gu, Seongnam 463-774, Korea Tel: +82-31-779-0063, Fax: +82-31-779-0635, E-mail: glide@dmc.or.kr

(c) This is an open-access article distributed under the terms of the Creative Commons Attribution Non-Commercial License (http://creativecommons. org/licenses/by-nc/3.0) which permits unrestricted noncommercial use, distribution, and reproduction in any medium, provided the original work is properly cited.

Copyright $\odot 2014$ by Korean Academy of Rehabilitation Medicine have a relapsing-remitting course with disease progression. However, central nervous system involvement is extremely rare. We report a case of IgG4-related sclerosing pachymeningitis causing paraplegia.

\section{CASE REPORT}

A 52-year-old female presented with sudden weakness of both lower extremities for two days. She showed paraplegia with motor power of Medical Research Council (MRC) grade 3/1. Pinprick and light touch sensations were impaired below T5 dermatome and she was unable to void. Magnetic resonance imaging revealed the tubular smooth-margined soft tissue mass which was diffusely compressing spinal cord with signal change in the subdural space, along the $\mathrm{C} 7$ to $\mathrm{T} 5$ levels (Fig. 1).

Laboratory findings were non-specific. Erythrocyte sedimentation rate $(67 \mathrm{~mm} / \mathrm{hr})$ and rheumatoid factor (51.81 IU/mL) were elevated, and antinuclear antibody 

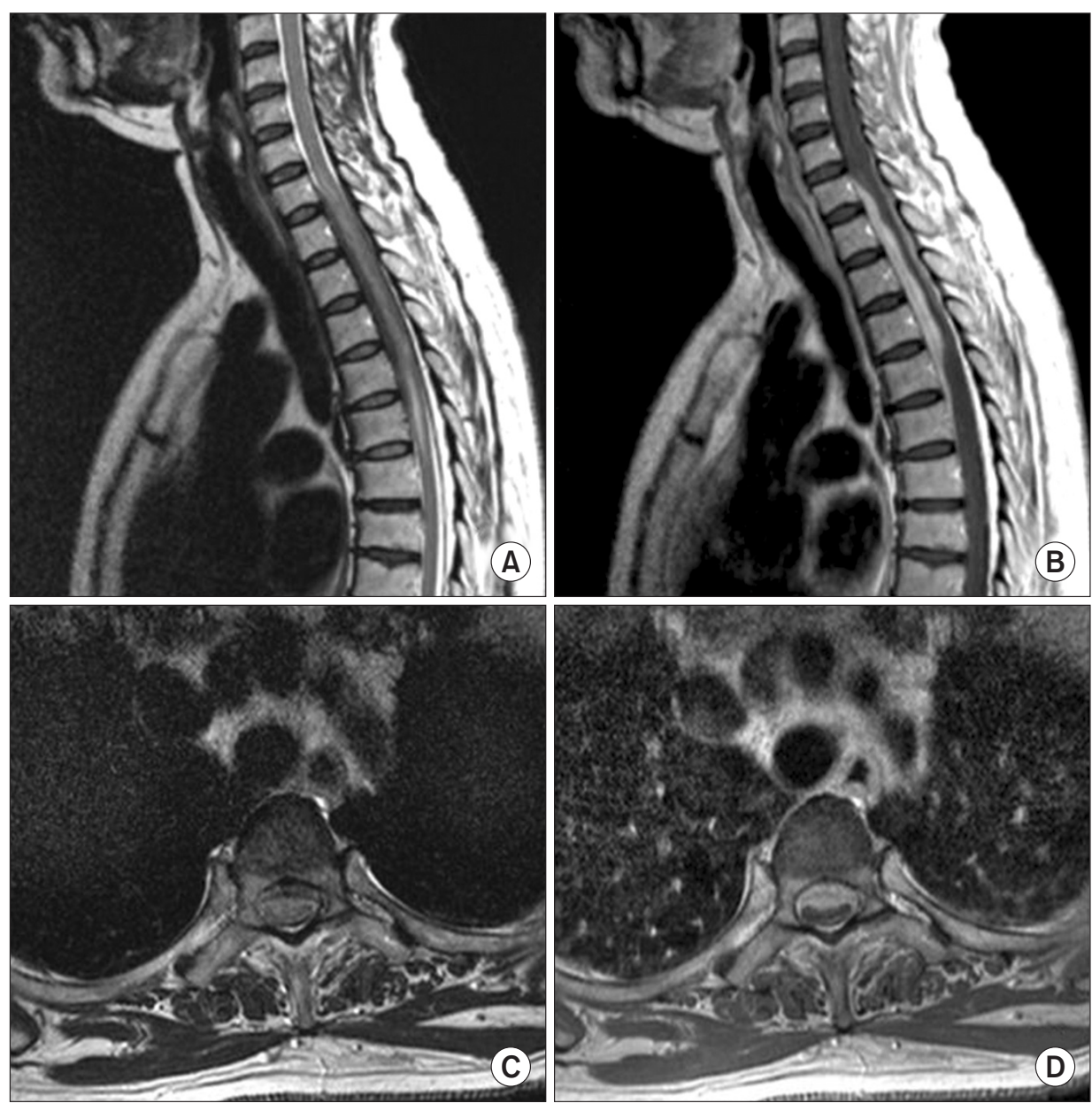

Fig. 1. Cervicothoracic magnetic resonance image shows tubular smooth-margined intradural extramedullary soft tissue mass from C7 to T5 levels with signal change on spinal cord. Sagittal T2-weighted (A) and gadoliniumenhanced T1-weighted (B) images. Axial T2-weighted (C) and gadolinium-enhanced T1-weighted (D) images.

was positive. Serum IgG and IgG4 level prior to steroid therapy and surgery were not obtained. Cerebrospinal fluid (CSF) profiles showed pleocytosis and elevated protein level (white blood cell $150 / \mu \mathrm{L}$, protein $865 \mathrm{mg} / \mathrm{dL}$ ). CSF IgG $(0.70 \mathrm{mg} / \mathrm{dL})$ level was in normal range.

Intravenous steroid pulse therapy was started. Unfortunately, her lower extremities weakness progressed to grade $1 / 1$. She underwent emergency operation. After laminotomy from the $\mathrm{C} 7$ to $\mathrm{T} 4$, the mass was totally removed (Fig. 2). There was moderate adhesion of the mass to the anterior dura. Low dose oral steroid was maintained after surgery.

The immunopathologic findings revealed the dense lymphoplasma cell infiltrations with fibrosis suspicious for IgG4-related sclerosing disease. Microscopic examination revealed the dura to be expanded by a dense polymorphous lymphoplasmacytic infiltration, accompanied by sclerotic fibrosis (Fig. 3A). Immunohistochemical staining using a panel of lymphoid markers including CD3,
CD5, CD20, and CD79a confirmed the lymphocytic infiltration to be polyclonal. Many plasma cells were positive to IgG4 (Fig. 3B).

Abdominopelvic, sialo and orbital computed tomography scan were performed to find other sites of involvement, but there were no remarkable findings.

After two months of comprehensive rehabilitation therapy, her neurologic level of injury remained $\mathrm{T} 5$, and only right knee extensor strength was improved to grade 2 .

\section{DISCUSSION}

Hypertrophic pachymeningitis (HP) is an inflammatory disorder which causes localized or diffuse thickening of the cranial or spinal cord dura mater. It is most often related to infectious, neoplastic, or immune-mediated conditions. Some cases with no known etiology are termed idiopathic hypertrophic pachymeningitis (IHP). IHP is diagnosed by exclusion of all other diseases that can 

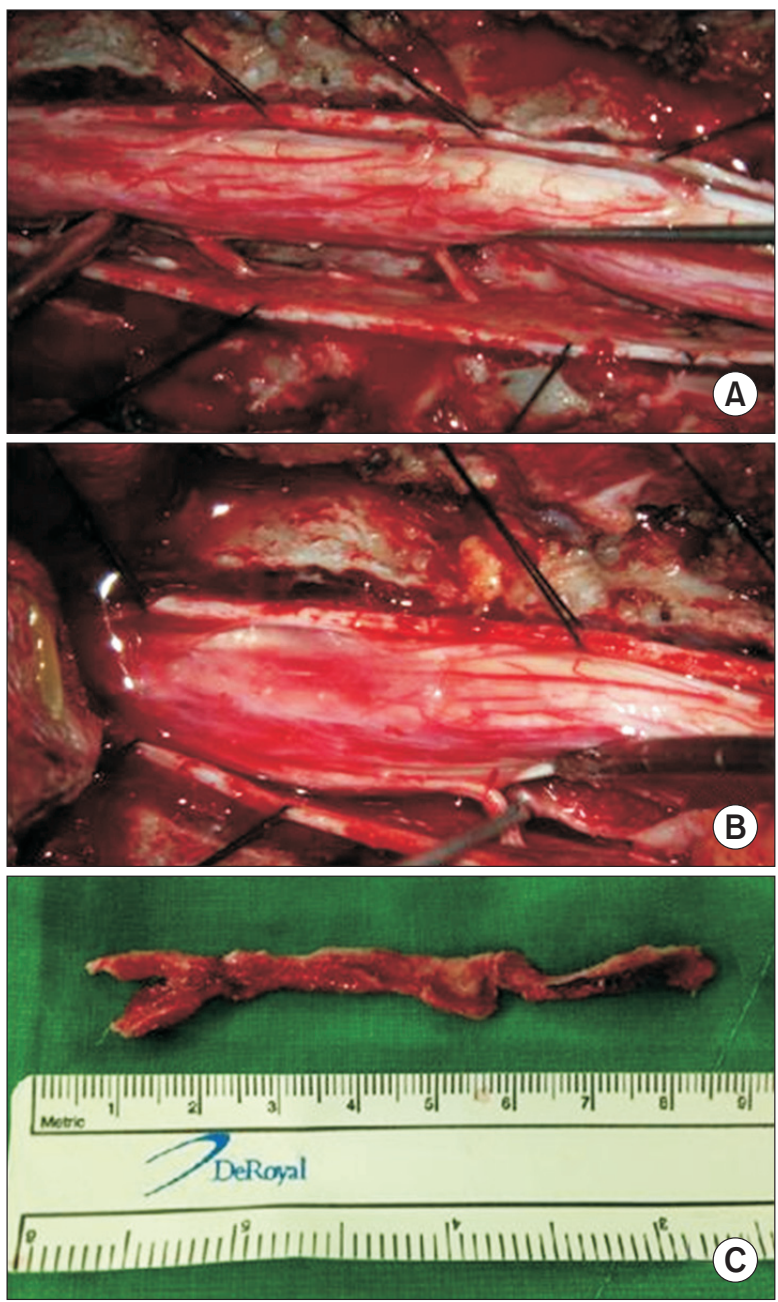

Fig. 2. Findings of intraoperative specimen. (A) Anterior located intradural extramedullary mass compressing the thoracic spinal cord. (B) Separation of the mass after sacrifice of the thoracic rootlets. (C) Whole mass after excision. cause HP. Recently, it has been suggested that some cases of previously diagnosed as IHP were the dural involvement of IgG4-related sclerosing disease [2].

IgG4-related sclerosing disease is a systemic disorder, characterized by a lymphoplasmacytic infiltration that stains positively for IgG4-bearing plasma cells in affected organs. It is often accompanied by a serum IgG4 level elevation and generally responds well to steroid therapy. The pathophysiology remains poorly understood, and it is still an ongoing challenge in diagnosis. Imaging, serology, histopathology, and response to steroid therapy are used to diagnose IgG4-related sclerosing pancreatitis [1]. However, there are no well established diagnostic criteria for extra-pancreatic involvement [3] and are often extrapolated from criteria for autoimmune pancreatitis. In this case, we performed various evaluations to find out the etiology, and we excluded tuberculosis, syphilis, other infections, and malignancy. We also could not find other organ involvement. Serum IgG4 level often correlates with disease activity and the number of involved organs [4]. Her serum IgG4 level was not obtained at the time of admission, but it was in normal range at three weeks after steroid administration and operation. Thus, it is not likely to have diagnostic value. The diagnosis depended on immunopathologic findings. A subset of inflammatory myofibroblastic tumor can exhibit high IgG4/IgG ratio, but there were no spindle cell infiltrations in this case $[5,6]$.

There are only a few reports of IgG4-related sclerosing pachymeningitis, especially involving spinal cord $[2,3,7-$ 10]. Chan et al. [7] and Choi et al. [8] reported cases of IgG4-related sclerosing pachymeningitis (Table 1). In both cases, the diagnosis was also based on immunopathologic findings. There were some differences in our case from previously reported cases. Initial symptom was
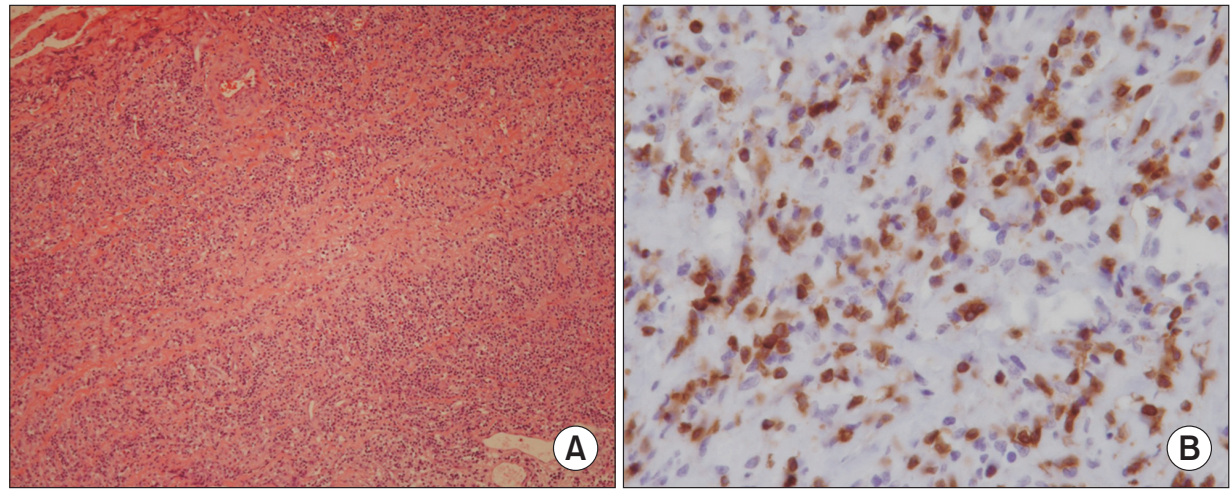

Fig. 3. Findings of microscopic examination. Dense lymphoid cell infiltration associated with fibrosis characterized by sclerotic collagen fibers. (A) The lymphoid cell infiltration consists of a mixture of mature plasma cells and small lymphocytes (H\&E stain, $\times 100$ ). (B) Immunostaining reveals IgG4 positive cells $(\times 400)$. 


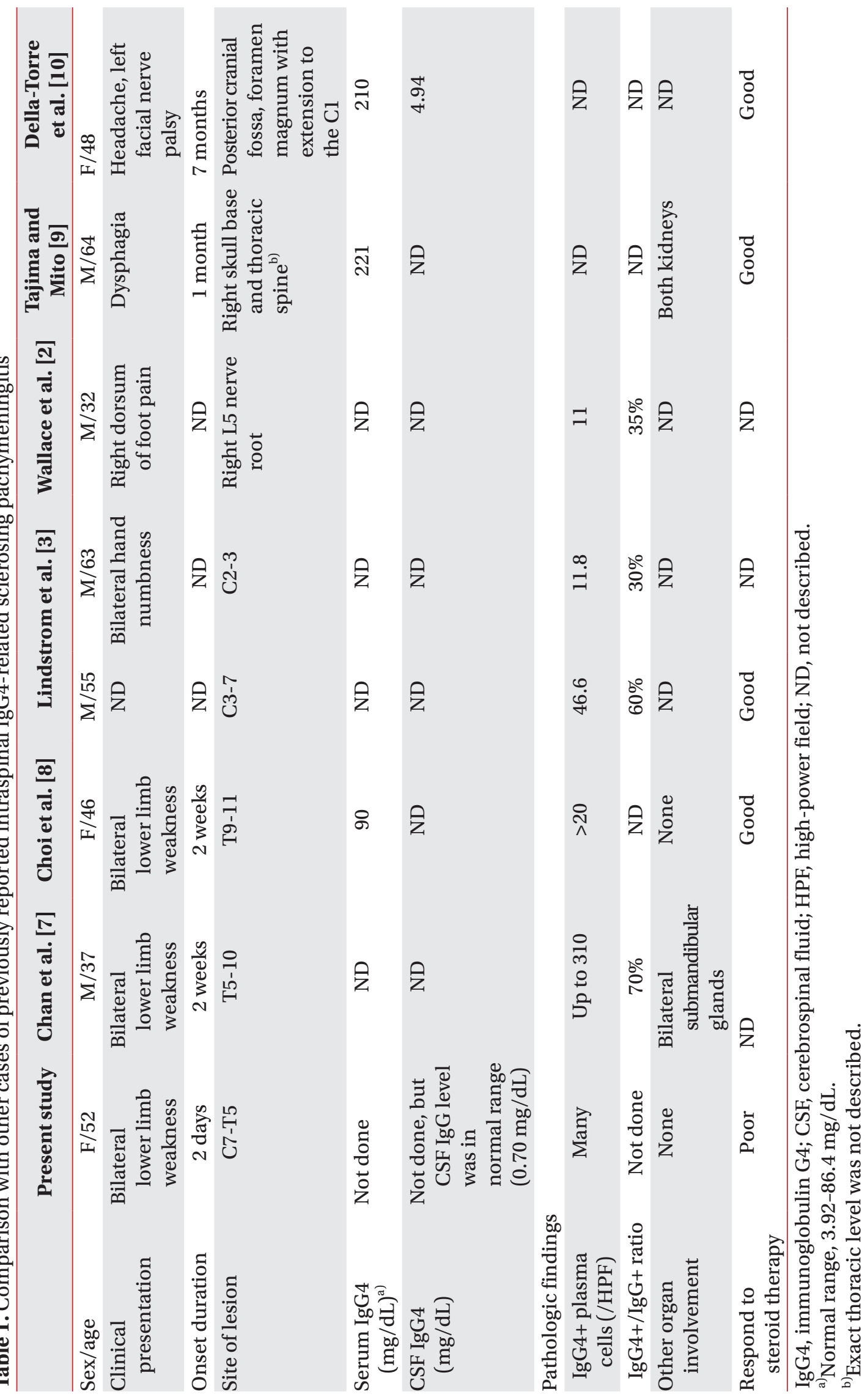


more severe and its progression was faster. She also did not respond well to steroid therapy.

We report a rare case of IgG4-related sclerosing disease involving spinal dura mater with detailed clinical data. Unlike previous reports, it can have rapid symptom progression and cause severe neurologic sequelae. IgG4related sclerosing disease should be considered, when evaluating the mass lesion around the spinal cord.

\section{CONFLICT OF INTEREST}

No potential conflict of interest relevant to this article was reported.

\section{REFERENCES}

1. Kamisawa T, Okamoto A. IgG4-related sclerosing disease. World J Gastroenterol 2008;14:3948-55.

2. Wallace ZS, Carruthers MN, Khosroshahi A, Carruthers R, Shinagare S, Stemmer-Rachamimov A, et al. IgG4-related disease and hypertrophic pachymeningitis. Medicine (Baltimore) 2013;92:206-16.

3. Lindstrom KM, Cousar JB, Lopes MB. IgG4-related meningeal disease: clinico-pathological features and proposal for diagnostic criteria. Acta Neuropathol 2010;120:765-76.

4. Hamano H, Kawa S, Horiuchi A, Unno H, Furuya N, Akamatsu T, et al. High serum IgG4 concentrations in patients with sclerosing pancreatitis. N Engl J Med 2001;344:732-8.

5. Saab ST, Hornick JL, Fletcher CD, Olson SJ, Coffin CM. IgG4 plasma cells in inflammatory myofibroblastic tumor: inflammatory marker or pathogenic link? Mod Pathol 2011;24:606-12.

6. Ishihara M, Izumoto S, Iwatsuki K, Yoshimine T. Immunohistochemical study of multiple inflammatory pseudotumors with both brain and spinal cord involvement: case report. Neurol Med Chir (Tokyo) 2010;50:246-50.

7. Chan SK, Cheuk W, Chan KT, Chan JK. IgG4-related sclerosing pachymeningitis: a previously unrecognized form of central nervous system involvement in IgG4-related sclerosing disease. Am J Surg Pathol 2009;33:1249-52.

8. Choi SH, Lee SH, Khang SK, Jeon SR. IgG4-related sclerosing pachymeningitis causing spinal cord compression. Neurology 2010;75:1388-90.

9. Tajima Y, Mito Y. Cranial neuropathy because of IgG4related pachymeningitis; intracranial and spinal mass lesions. BMJ Case Rep 2012 Jul 19 [Epub]. http:// dx.doi.org/10.1136/bcr-2012-006471.

10. Della-Torre E, Passerini G, Furlan R, Roveri L, Chieffo $\mathrm{R}$, Anzalone N, et al. Cerebrospinal fluid analysis in immunoglobulin G4-related hypertrophic pachymeningitis. J Rheumatol 2013;40:1927-9. 